\title{
Primary pulmonary choriocarcinoma in a male
}

\author{
Akberet Hadgu, ${ }^{1}$ Arshdeep Tindni, ${ }^{2}$ Mukta Panda ${ }^{3}$ \\ ${ }^{1}$ College of Medicine, University of Tennessee, Chattanooga, Tennessee, USA \\ ${ }^{2}$ Division of Nephrology and Hypertension, University of Cincinnati Medical Center, Cincinnati, Ohio, USA \\ ${ }^{3}$ Department of Medicine, University of Tennessee, Chattanooga, Tennessee, USA \\ Correspondence to Akberet Hadgu, akbereth@yahoo.com
}

\begin{abstract}
Summary
\section{BACKGROUND}

Primary pulmonary choriocarcinoma is a very rare entity with very poor prognosis as compared to its testicular counterpart. Often primary choriocarcinoma of the lung in men is misdiagnosed as more common diseases, such as primary or metastatic lung cancer, and therefore potentially curative chemotherapy or surgery may be delayed.
\end{abstract}

The authors report a case of a 48-year-old male smoker who presented with respiratory distress and constitutional symptoms along with gynaecomastia and multiple pulmonary nodules. Based on normal physical and ultrasound findings of the testes, presence of markedly elevated serum $\beta$ human chorionic gonadotrophin (HCG) and biopsy findings of the lung a diagnosis of primary pulmonary choriocarcinoma was made.

were also normal. MRI of the brain showed less than $1 \mathrm{~cm}$ probable metastatic lesion in the left thalamus and right subcortical matter (figure 5). However due to the small size and depth of lesions the neurosurgical consultants indicated that biopsy was not feasible. Due to the normal high resolution ultrasound scan of the testes and absence of retroperitoneal mass and extent of pulmonary involvement the

\section{CASE PRESENTATION}

A 48-year-old white male with no significant past medical history presented with complaints of progressive shortness of breath, cough productive of thick whitish sputum, drenching night sweats, diminished appetite and unquantified weight loss which progressed over a period 2 weeks. No history of haemoptysis, chest pain, fever or chills. He has a smoking history of 25 pack years and remote history of marijuana use. On examination patient was afebrile with a heart rate of 105 beats $/ \mathrm{min}$ and respiratory rate of $25 / \mathrm{min}$ and saturation of $94 \%$ on 41 of oxygen. Chest exam revealed diffuse coarse inspiratory crackles and gynaecomastia. Genital exam did not reveal any scrotal mass. The remainder of the physical examination was unremarkable. Laboratory data was significant for white blood cell 14 900/ $\mathrm{mm}$, haemoglobin $14 \mathrm{~g} / \mathrm{dl}$; comprehensive metabolic profile was within normal limits except for aspartate transaminase $77 \mathrm{U} / 1$, alanine transaminase $62 \mathrm{U} / 1$, alkaline phosphatase $253 \mathrm{U} / \mathrm{l}$ and albumin $1.9 \mathrm{mg} / \mathrm{dl}$. Other significant laboratory data was $\beta$ human chorionic gonadotrophin (HCG) $16634 \mathrm{mIU} / \mathrm{ml}$, lactic dehydrogenase $572 \mathrm{mg} / \mathrm{dl}$, normal serum $\alpha$-fetoprotein and negative HIV test. Chest $\mathrm{x}$-ray was significant for bilateral pulmonary nodules (figure 1). Doppler ultrasound of the testes and mammography of breasts were negative for malignancy (figure 2). CT scan of the chest and abdomen revealed extensive lymphadenopathy in the mediastinum extending to the para tracheal area with extensive and multiple bilateral pulmonary nodules (figure 3 ) and multiple low density filling defects in the liver some with thick vascular walls. These findings were suspicious for a combination of cysts and metastasis of the liver (figure 4). There was no retroperitoneal tumour or lymphadenopathy and other visceral organs urology and oncology consultants agreed not to proceed with exploration and orchiectomy. CT guided biopsy of right lung lesion showed the majority of the neoplasm to be necrotic and hemorrhagic, with the few viable islands demonstrating syncytiotrophoblastic and cytotrophoblasticlike cells, with immunohistochemical results consistent with choriocarcinoma (figure 6). Based on the above findings a diagnosis of primary pulmonary choriocarcinoma with probable metastasis to the liver and brain was made.

\section{TREATMENT}

The patient received four cycles of $20 \mathrm{mg} / \mathrm{m}^{2}$ of cisplatin, $100 \mathrm{mg} / \mathrm{m}^{2}$ of etoposide and 30 units of bleomycin per standard protocol.

\section{OUTCOME AND FOLLOW-UP}

During the course of treatment pulmonary function test was monitored and remained unchanged from baseline. Patient showed marked clinical improvement. Serum $\beta$ HCG dropped from 16000 to 900. Patient continued to do well and after the fourth cycle of chemotherapy, serum $\beta$ HCG dropped further to 11. However follow-up CT scan of the chest for restaging revealed significant bulk of tumour (figure 7). Postchemotherapy thoracoscopic wedge resection of the left lower lobe revealed persistence of malignant cells consistent with choriocarcinoma. Patient rapidly deteriorated after surgery with respiratory failure and died 5 days after.

\section{DISCUSSION}

Extragonadal germ cell tumours (EGCT) represent 2-5\% of all germ cell tumours. ${ }^{1}$ Primary chriocarcinoma is one of the non-seminomatous EGCT that occur mostly in young men. 


\section{BMJ Case Reports}

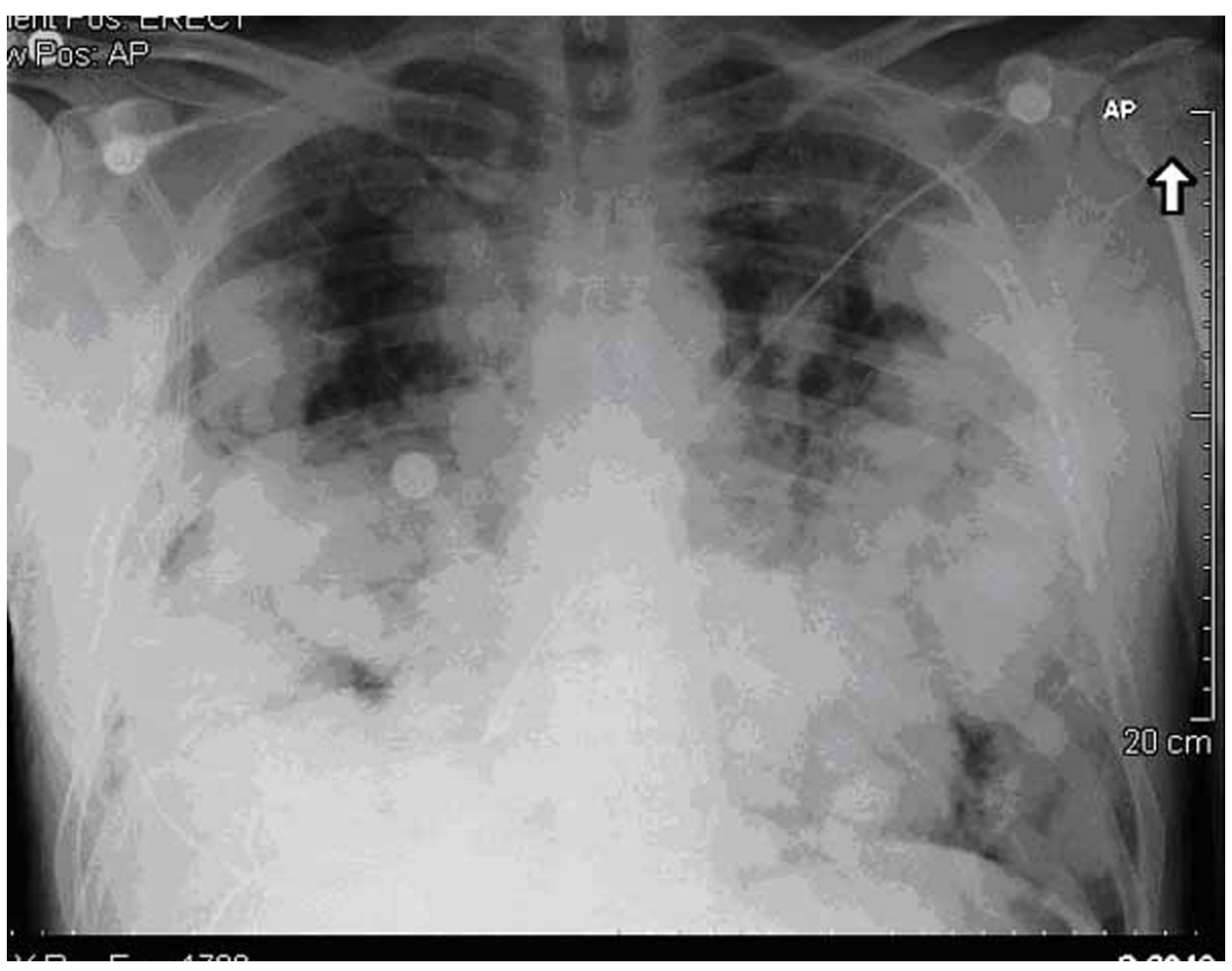

Figure 1 Chest x-ray showing bilateral pulmonary nodules.

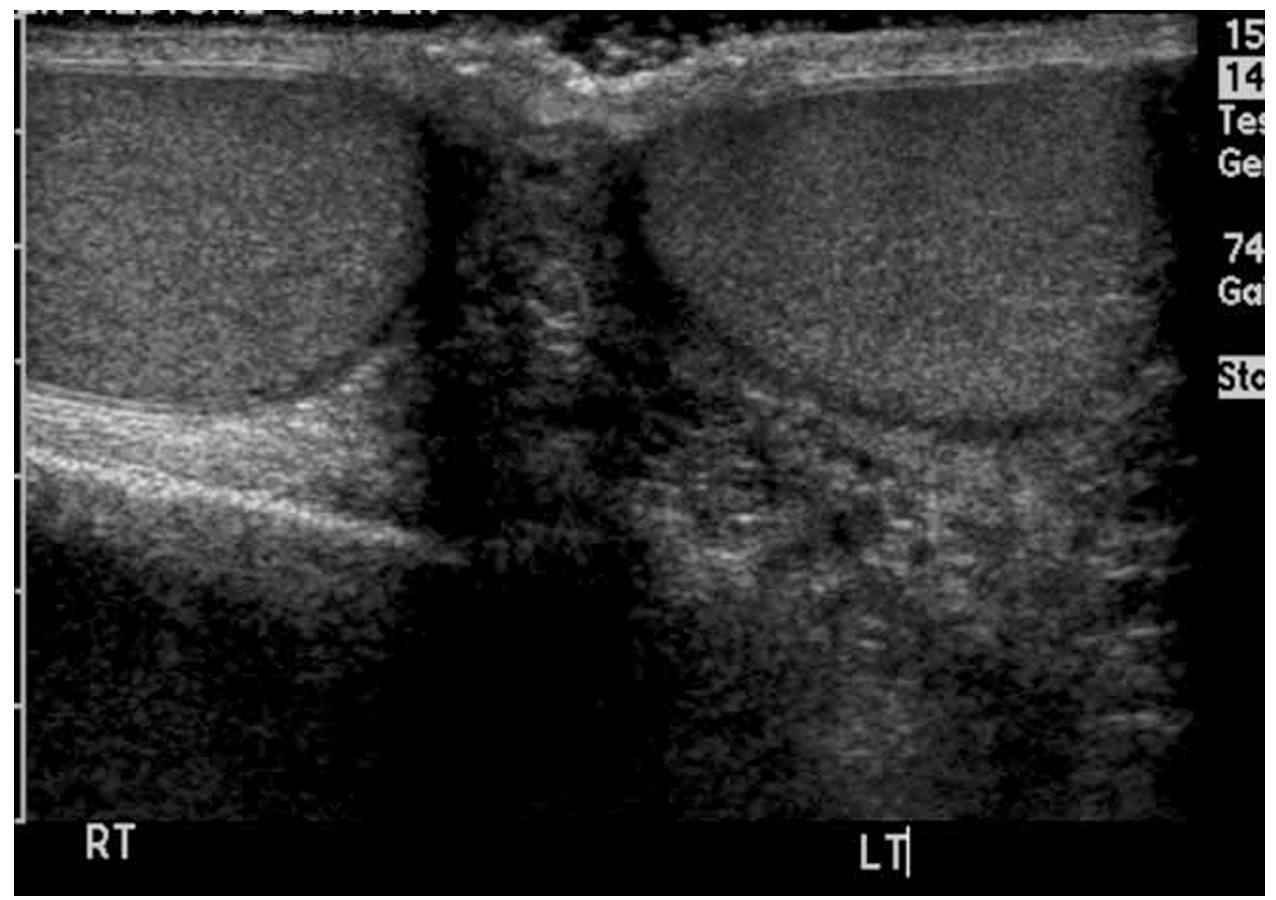

Figure 2 Normal ultrasound of testis.

An international analysis of 635 cases of EGCT of the mediastinum and retroperitoneum has shown ages ranging from 14 to 79 with a median age of 30 years. ${ }^{2}$ Primary choriocarcinoma is an exceedingly rare and aggressive tumour with much worse prognosis than other histologic subtypes owing to the haematogeneous dissemination at the time of diagnosis.

Most cases arise in the midline structures such as the pineal gland, mediastinum and retroperitoneum in keeping with the theory of mismigration of primordial germ cells 


\section{BMJ Case Reports}

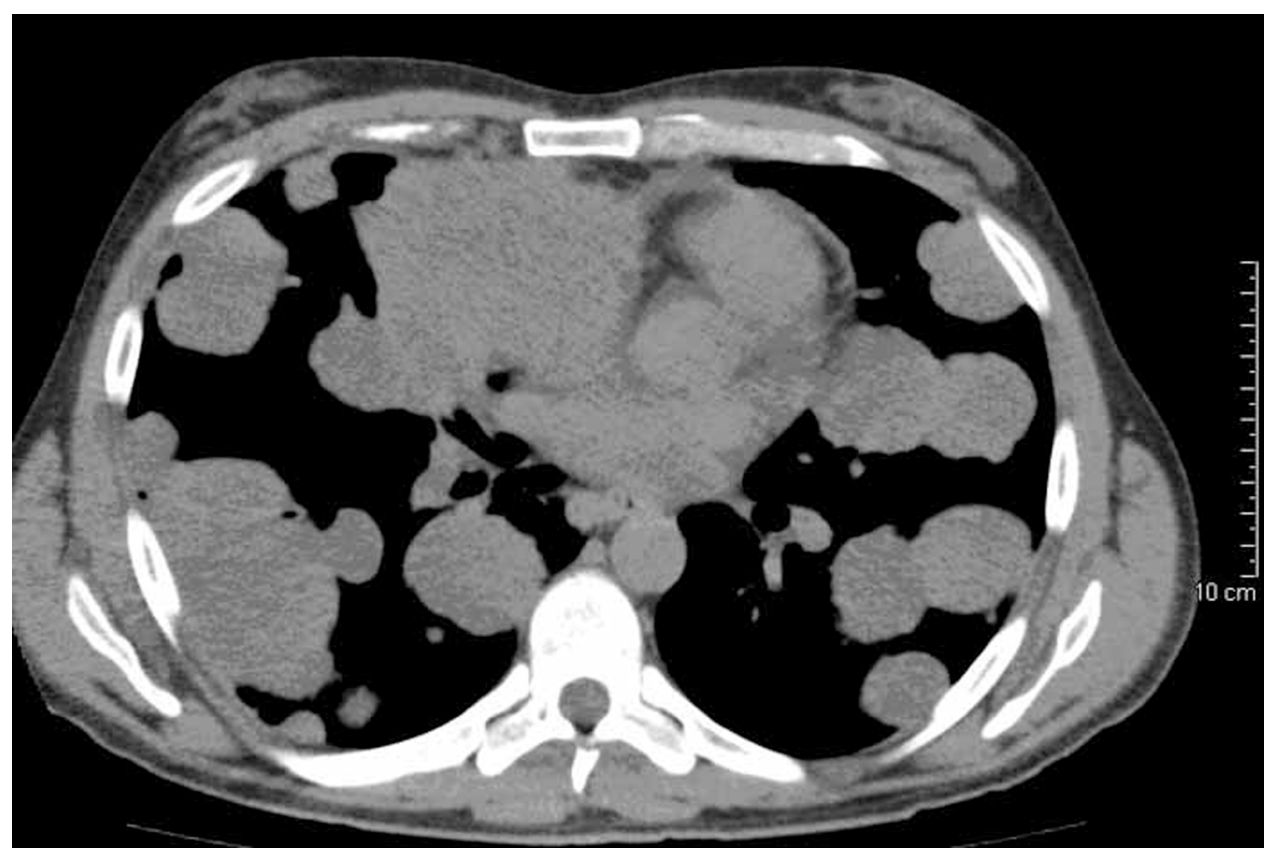

Figure 3 CT chest (before chemotherapy) showing extensive lymphadenopathy in the mediastinum with extensive and multiple bilateral pulmonary nodules.

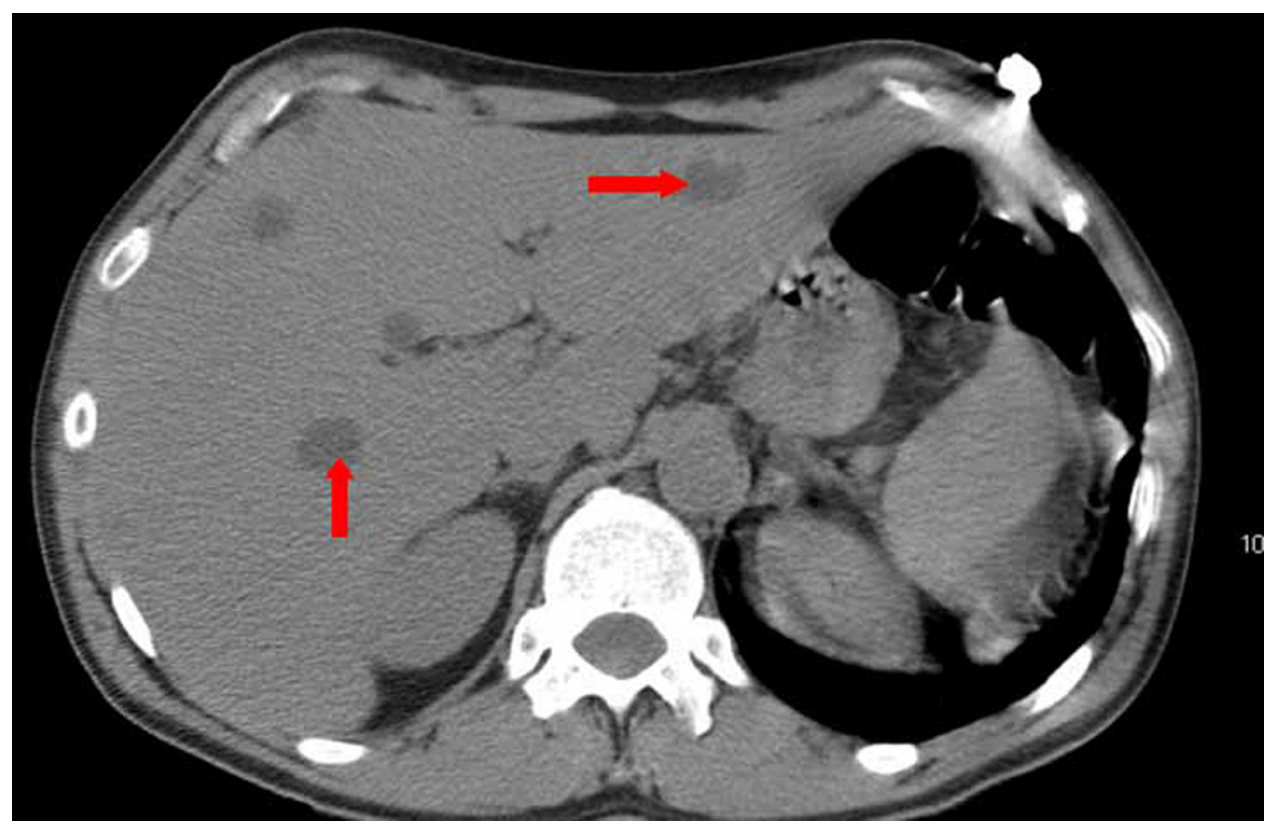

Figure 4 CT abdomen showing multiple low density filling defects in the liver.

along the urogenital ridge during embryogenesis. However cases with involvement of other visceral organs such as the lungs, brain, stomach, small bowel, kidneys and adrenals have been reported. ${ }^{3}$ Primary pulmonary choriocarcinoma in male is very rare with 14 cases so far reported. ${ }^{4,5}$

The origin of EGCT especially primary choriocarcinoma has been a topic of controversy and debate. One hypothesis is the reverse migration of occult carcinoma in situ in the gonad with subsequent spontaneous necrosis of the primary with formation of a scar tissue thus the "burnt out phenomenon'. However several authors have challenged this concept. Serial sectioning of the testes at autopsy failed to reveal a primary lesion or scar indicative of the burn out tumour. ${ }^{6,7}$ In addition some authors explain that the presence of scars may be merely the result of trauma and the small teratomas may be secondary to hormonal stimulation from the choriocarcinoma and as such it does not establish the gonad as the primary site of the neoplasm. ${ }^{8,9}$ Review of the literature support that EGCT represent malignant transformation of local primordial germ cells without a gonadal 


\section{BMJ Case Reports}
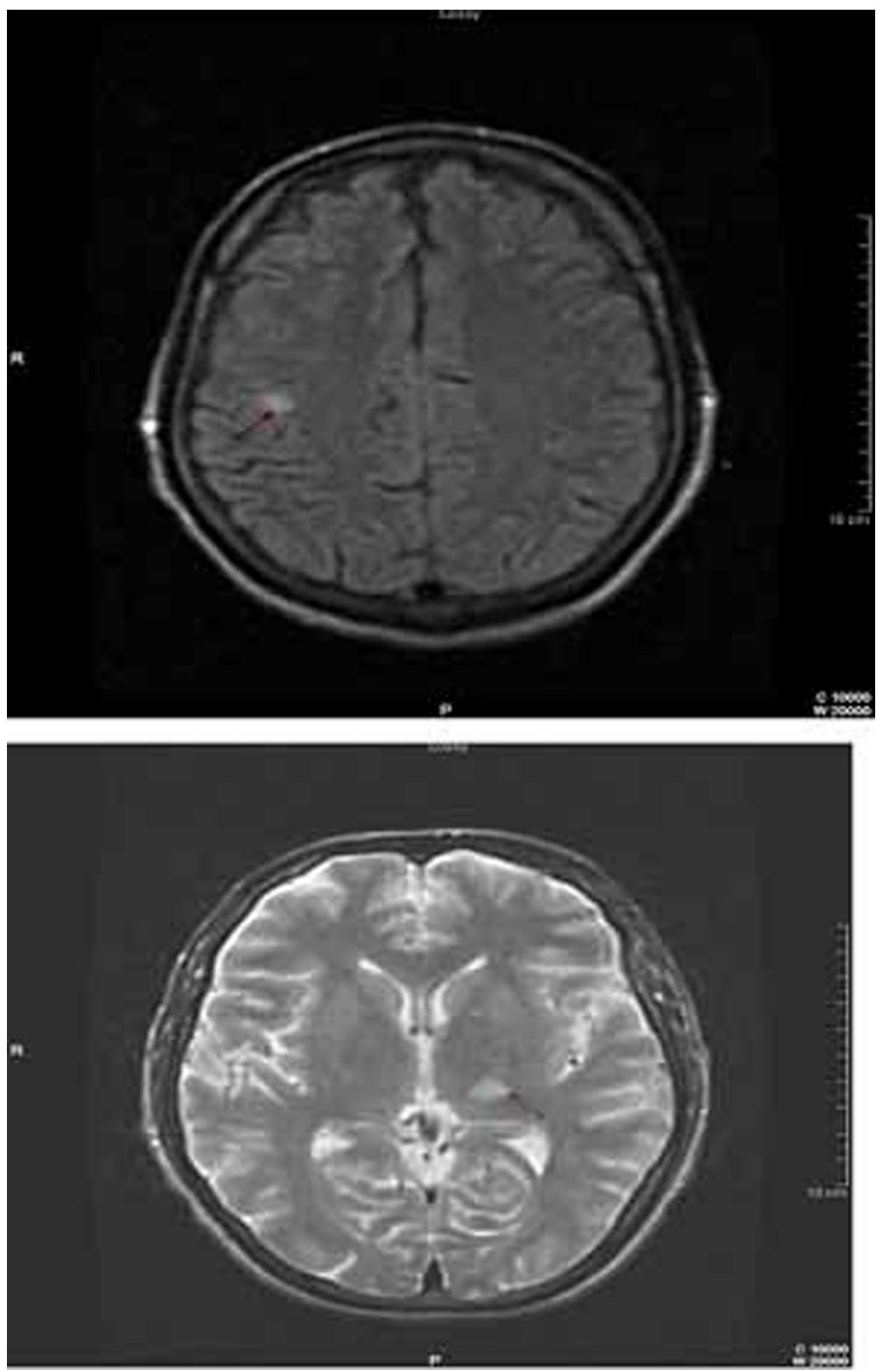

Figure $5 \mathrm{MRI}$ brain showing metastatic lesion in the left thalamus and right sub cortical matter.

focus and a routine bilateral testicular biopsy is not recommended. ${ }^{6,9,10}$

Clinical presentation depends on the location and size of tumour. In a recent meta-analysis representing the largest published series of EGCT with 635 patients, those with mediastinal tumour initially presented with dyspnea, cough and chest pain followed by fever weight loss, superior vena cava syndrome, fatigue and weakness. ${ }^{2}$

Gynaecomastia has been associated with several conditions both physiologic and pathologic. It can be a result of primary or secondary gonadal failure, liver disease, hyperthyroidism, renal disease and haemodyalysis, testicular and 


\section{BMJ Case Reports}

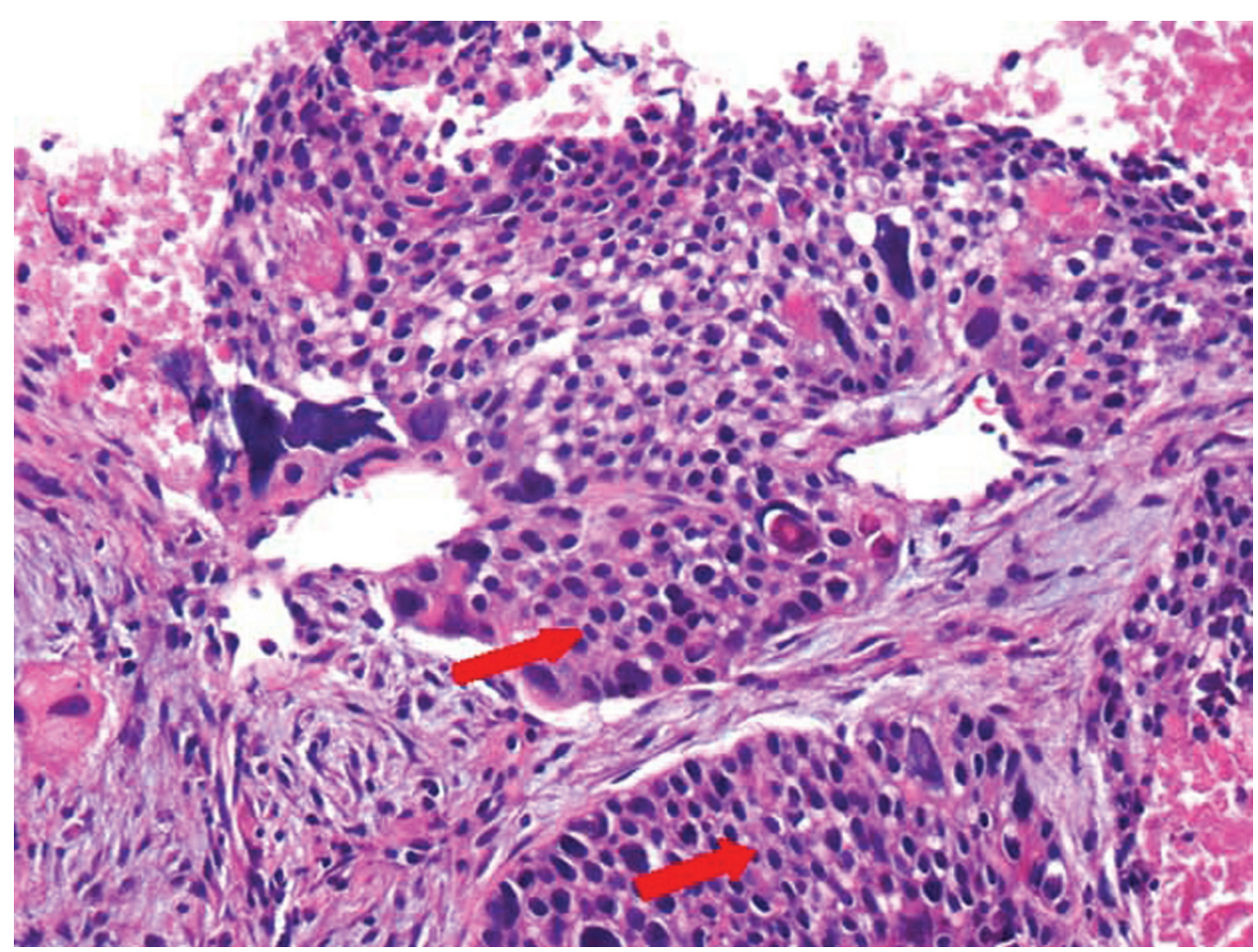

Figure 6 CT guided biopsy of left lung lesion showing syncytiotrophoblastic and cytotrophoblastic-like cells with immunohistochemical results consistent with choriocarcinoma.

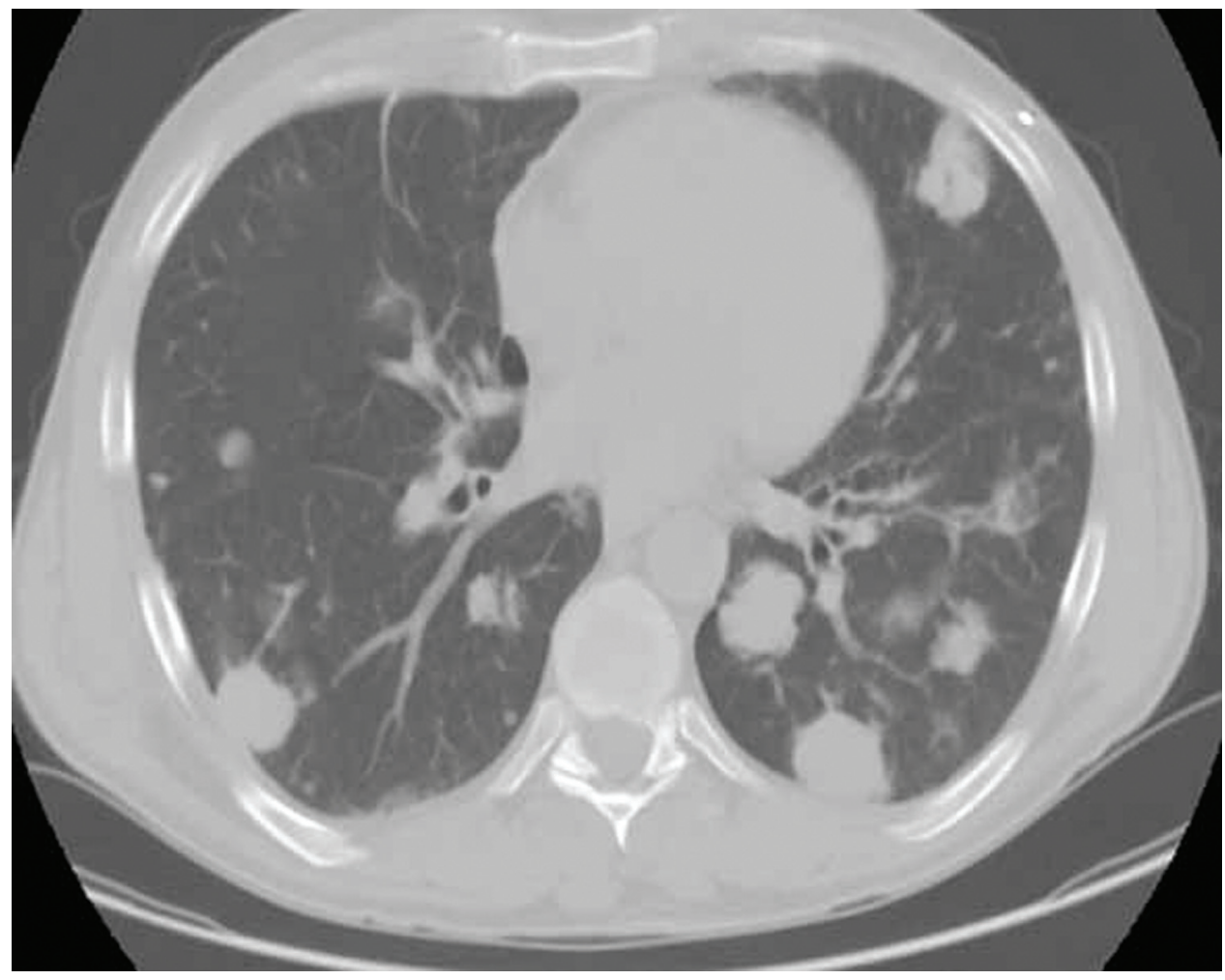

Figure 7 CT chest (after chemotherapy) some resolution of the tumour burden. 


\section{BMJ Case Reports}

adrenal neoplasms, ectopic production of $\beta$ HCG by lung, kidney and liver cancer. ${ }^{11}$ Numerous drugs such as androgens and anabolic steroids, H2 blockers, cardiovascular drugs, psychoactive agents, antibiotics and antifungals, alkylating agents, anticonvulsants, alcohol, marijuana, heroin and amphetamine abuse has also been linked to the development of gynaecomastia. ${ }^{11}$ The presence of gynaecomastia in a male patient with bilateral pulmonary nodules however is virtually diagnostic of choriocarcinoma until proven otherwise and as such should prompt the clinician to get a urine pregnancy test there by avoiding delay in diagnosis and treatment. ${ }^{5,8}$ Definitive diagnosis is made with tissue biopsy.

Standard treatment of primary pulmonary choriocarcinoma is four cycles of cis-platin based chemotherapy followed by radical resection of all residual masses when technically feasible. Salvage chemotherapy is utilised for patients with relapse of the disease. Despite current treatment prognosis remains to be extremely dismal especially for those with pulmonary and other visceral involvement at presentation and treatment resistance.

We recognise the diagnosis of primary pulmonary choriocarcinoma should be made after careful consideration of many of the existing hypothesis. To this effect we have considered the following findings before making the diagnosis. On reviewing the literature, multiple pulmonary nodules have been reported as a radiological manifestation of primary pulmonary choriocarcinoma. ${ }^{5}$ The absence of testicular mass in the phase of wide spread metastatic disease is very uncommon. ${ }^{12}$

Even though we do not agree with the concept of 'burnt out testicular focus' current high resolution ultrasonography of the testes has proven to detect non-palpable intratesticular masses and calcifications that correlate very well with pathological characteristics of burnt out tumours. ${ }^{13}$ This has been confirmed in several retrospective reviews of patients with clinically normal testes and a diagnosis of presumed EGCT that underwent ultrasonography. ${ }^{12-15}$ Our patient had a normal testicular ultrasound as well as normal CT scan of the retroperitoneum and pelvis.

Testicularchoriocarcinoma has relatively a better response to the current standard cis-platin based chemotherapy. In the case of our patient, he presented with advanced disease with evidence of metastasis to the liver and brain which rendered the tumour to be resistant to treatment.

\section{Learning points}

- Primary pulmonary choriocarcinoma in the male is an exceedingly rare and aggressive non-seminomatous EGCT.

- The presence of gynaecomastia in a male patient with bilateral pulmonary nodules should raise a clinical suspicion of primary choriocarcinoma there by prompting the clinician to perform a thorough testicular examination along with high resolution ultrasonography of the testes to rule out a testicular primary.

- Urine or serum $\beta$ HCG is a quick and affordable test that will help make a rapid diagnosis, there by preventing delay in diagnosis and potentially curative treatment.
Suresh Enjeti, Division Chief and Associate Professor, Pulmonology; John McCravey, Clinical Assistant Professor, Oncology.

\section{Competing interests None.}

Patient consent Obtained.

\section{REFERENCES}

1. Collins DH, Pugh RC. Classification and frequency of testicular tumours. Br J Urol 1964;36(Suppl):1-11.

2. Bokemeyer C, Nichols CR, Droz JP. Extragonadal germ cell tumors of the mediastinum and retroperitoneum: results from an international analysis. J Clin Oncol 2002;20:1864-73.

3. Fine G, Smith RWJr, Pachter MR. Primary extragenital choriocarcinoma in the male subject. Case report and review of the literature. Am J Med 1962;32:776-94.

4. Ikura Y, Inoue T, Tsukuda H. Primary choriocarcinoma and human chorionic gonadotrophin-producing giant cell carcinoma of the lung: are they independent entities? Histopathology 2000;36:17-25.

5. Tsai JR, Chong IW, Hung JY. Use of urine pregnancy test for rapid diagnosis of primary pulmonary choriocarcinoma in a man. Chest 2002;121:996-8.

6. Hainsworth JD, Greco FA. Extragonadal germ cell tumors and unrecognized germ cell tumors. Semin Oncol 1992;19:119-27.

7. Luna MA, Valenzuela-Tamariz J. Germ-cell tumors of the mediastinum, postmortem findings. Am J Clin Pathol 1976;65:450-4.

8. Holt LP, Melcher DH, Colquhoun J. Extra-gonadal choriocarcinoma in the male. Postgrad Med J 1965:41:134-8.

9. Lynch MJG, Blewett GL. Choriocarcinoma arising in the male mediastinum Thorax 1953;8:157

10. Schmol HJ, . Extragonadal germ cell tumors. Ann Oncol 2002;13 (Suppl 4):265-72

11. Braunstein GD, Gynecomastia. N Eng/ J Med 1993;328:490-5.

12. Kirschling RJ, Kvols LK Charboneau JW. High-resolution ultrasonographic and pathologic abnormalities of germ cell tumors in patients with clinically normal testes. Mayo Clin Proc 1983;58:648-53.

13. Comiter CV, Benson CJ, Capelouto CC. Nonpalpable intratesticular masses detected sonographically. J Urol 1995;154:1367-9.

14. Shawker TH, Javadpour N, O'Leary T. Ultrasonographic detection of "burned-out" primary testicular germ cell tumors in clinically normal testes. J Ultrasound Med 1983;2:477-9.

15. Comiter CV, Renshaw AA, Benson CB. Burned-out primary testicular cancer: sonographic and pathological characteristics. J Urol 1996;156:85-8. 


\section{BMJ Case Reports}

This pdf has been created automatically from the final edited text and images.

Copyright 2010 BMJ Publishing Group. All rights reserved. For permission to reuse any of this content visit http://group.bmj.com/group/rights-licensing/permissions. BMJ Case Report Fellows may re-use this article for personal use and teaching without any further permission.

Please cite this article as follows (you will need to access the article online to obtain the date of publication).

Hadgu A, Tindni A, Panda M. Primary pulmonary choriocarcinoma in a male. BMJ Case Reports 2010;10.1136/bcr.02.2010.2712, date of publication

Become a Fellow of BMJ Case Reports today and you can:

- Submit as many cases as you like

Enjoy fast sympathetic peer review and rapid publication of accepted articles

Access all the published articles

- Re-use any of the published material for personal use and teaching without further permission

For information on Institutional Fellowships contact consortiasales@bmjgroup.com

Visit casereports.bmj.com for more articles like this and to become a Fellow 